\title{
UV absorption detection with a packed flow cell in microcolumn liquid chromatography
}

\author{
T. Enami and N. Nagae
}

Nomura Chemical Co., 851 Anada-cho, Seto 489-0003, Japan

\begin{abstract}
A packed flow cell was used for UV absorption detection in microcolumn liquid chromatography (LC). The flow cell consisted of fused-silica tubing packed with the same material as in the separation column. A focusing effect of the stationary phase on the signal intensity was observed.
\end{abstract}

$\mathrm{n}$-column detection has been proposed as a strategy for elimination of zone broadening effects caused by extra column volumes inherent to detector cells and associated with coupling fittings in microcolumn LC [1-4]. On-column detection has been investigated not only for open-tubular capillary columns [1-4] but also packed columns [5-7]. Takeuchi and Ishii reported that on-column detection in the presence of a stationary phase provides increased sensitivity by a factor of $\Psi(1+k) /(1+\Psi)$ compared with post-column detection, where $\Psi$ and $k$ are the phase ratio and the retention factor of an analyte, respectively [5]. Furthermore, they pointed out a signal enhancement due to both focusing and environmental effects of the stationary phase in on-column fluorimetric detection.

On-column detection is defined here as a case when analytes are detected in the presence of a stationary phase. When a flow cell packed with the same materials as in the separation column is employed, the detection system still functions as it does when the separation column itself is subject to detection [6,7]. The use of a packed flow cell facilitates handling and replacement of the separation columns. On the other hand, Post-column detection is defined here as a case when analytes are detected in the absence of a stationary phase.

This article describes the use of a packed flow cell for UV absorption detection in microcolumn LC and signal enhancement of vitamins using octadecylsilyl-bonded silica (ODS) as packing materials for both the separation column and the packed flow cell.

\section{Experimental}

\section{Apparatus}

A microcolumn LC system was assembled from a Microfeeder pump (Azumadenki Kogyo, Tokyo, Japan) equipped with an MS-GAN 050 gas-tight syringe $(0.5 \mathrm{~mL}$; Ito, Fuji, Japan), a Model 7125 injector with a $20 \mu \mathrm{L}$ loop
(Rheodyne, Cotati, CA, USA), a $150 \times 0.3 \mathrm{~mm}$ i.d. separation column, a UV-970 Intelligent UV/VIS Detector (Jasco) with a laboratory-made flow cell, and an SIC 480 data station (SIC, Tokyo, Japan). The empty and packed flow cells were prepared from fused-silica tubing of $0.25 \mathrm{~mm}$ i.d. (Moritex, Tokyo, Japan) by the method reported previously [8]. The packed flow cell was prepared with the same ODS as in the separation column. The structures of both the empty and packed flow cells are shown in figure 1. The connecting stainless steel tubing between the injector and the separation column (Nomura Chemical, Seto, Japan) consisted of 1/16" o.d. tubing on one side and $1 / 32$ " o.d. tubing on another side because the fitting sizes of the injector and the separation column were $1 / 16$ " and $1 / 32$ ", respectively. The fused-silica tubing of $0.06 \mathrm{~mm}$ i.d. (S.G.E., Melbourne, Australia) was used as the connecting tubing between the separation column and the flow cell. Develosil ODS-UG-5 $150 \times 0.3 \mathrm{~mm}$ i.d. column (Nomura Chemical, Seto, Japan) was used as the separation column. The flow-rate of eluent was $4.2 \mu \mathrm{L} / \mathrm{min}$. The separation was carried out at room temperature.

\section{Reagents}

The reagents employed in this work were obtained from Wako Pure Chemical Industries (Osaka, Japan).

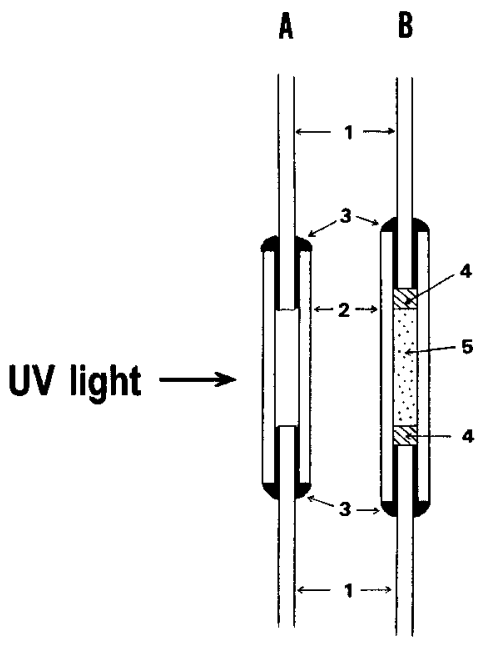

Figure 1. Structures of empty (A) and packed (B) flow cells. 1 = fused-silica tubing $0.06 \mathrm{~mm}$ i.d. $\times 0.22 \mathrm{~mm}$ o.d.; 2 = fusedsilica tubing $0.25 \mathrm{~mm}$ i.d. $\times 0.50 \mathrm{~mm}$ o.d.; $3=$ epoxy-resin adhesive; 4 = quarts wool; 5 = packing materials. 


\section{Results and discussion}

On-column detection with a packed flow cell has mainly been applied to fluorimetry. In the case of on-column UV absorption detection, UV light must pass through the packing materials. In this study, the UV light penetrated the packed flow cell of $0.25 \mathrm{~mm}$ i.d. perpendicularly. Therefore, the pass length of this flow cell was $0.25 \mathrm{~mm}$ at maximum, and even if the flow cell was packed with packing materials, UV light still could pass through it. Consequently, on-column UV absorption detection could be achieved.

Figure 2 demonstrates the UV spectra of pyrene detected on a packed flow cell and an empty flow cell. Aqueous acetonitrile solutions with various compositions including $0.62 \mathrm{mg} / \mathrm{dm}^{3}$ pyrene were passed into the packed flow cell to obtain UV spectra. As a reference, acetonitrile including $50 \mathrm{mg} / \mathrm{dm}^{3}$ pyrene was passed into the empty flow cell and the spectrum was measured ((a) in Fig. 2). After the analyte was dynamically equilibrated, each spectrum was measured. Since the partition of pyrene onto the stationary phase increases with increasing concentration of water in the solution, the higher the concentration of water in the solution, the higher the UV absorption of an analyte. The profiles of the spectra obtained by the on-column detection were almost the same as those obtained by using an empty flow cell at a wavelength in the range of 220 to $380 \mathrm{~nm}$. Effect of the stationary phase on the spectrum profile of an analyte was not found at a wavelength longer than $220 \mathrm{~nm}$.

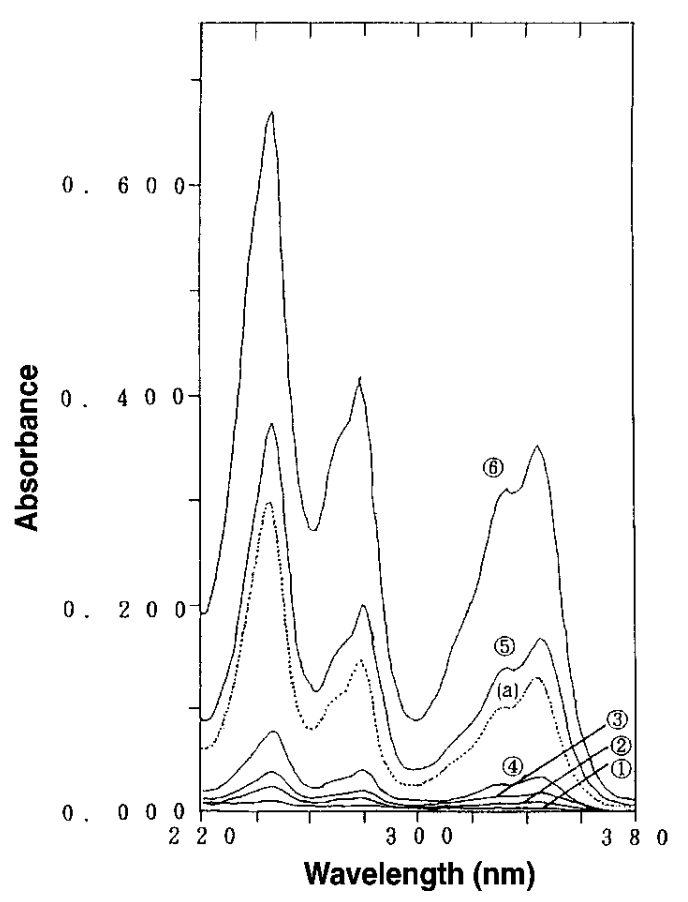

Figure 2. UV spectra of pyrene using on-column and post-column detection. Eluent, acetonitrile-water, (1) 10:0, (2) 7:3, (3) 6:4, (4) $5: 5$, (5) $4: 6$, (6) $3: 7$ including $0.62 \mathrm{mg} / \mathrm{dm}^{3}$ pyrene for on-column detection and acetonitrile including $50 \mathrm{mg} / \mathrm{dm}^{3}$ pyrene for on-column detection and acetonitrile including $50 \mathrm{mg} / \mathrm{dm}^{3}$ pyrene for post-column detection.
Figure 3 shows the chromatograms of an artificial mixture of fat-soluble vitamins obtained with an empty flow cell (A) and a packed flow cell (B), where the isocratic separation is carried out by using methanol-acetonitrile (40:60) as the mobile phase and injecting $15 \mu \mathrm{L}$ of the sample solution which is more than 2 times the separation column volume. The detection wavelength was $280 \mathrm{~nm}$. In this study, the on-column enrichment was also carried out. When the sample solution contains more water than the mobile phase in reversed-phase LC, the sample is concentrated on the stationary phase in the column inlet. This is because water-rich solvent as the sample solution works as the mobile phase first. The on-column enrichment allowed injection of a large volume of the sample solution onto the separation column and improved the concentration detection limits and sample loss. In fact, micro volume injection using an injector with less than a $0.1 \mu \mathrm{L}$ loop is impractical, especially in the analysis of biological samples, even if it is used in microcolumn LC. As shown in figure 3, the on-column enrichment yielded a positive ghost peak for post-column detection and a negative ghost peak for oncolumn detection without retaining on the column by eluting of the solvent in which the sample was dissolved. Therefore, the peak of an analyte with little retention on the column was hidden by the ghost peak.

The noise levels observed for both detection systems were nearly the same, e.g., $0.23 \mathrm{mAbs}$. for the post-column detection and $0.25 \mathrm{mAbs}$. for the on-column detection. It was found that the peak height increased with increasing retention factor for the on-column detection compared with that for the post-column detection. Consequently, better sensitivity could be achieved by the on-column detection. The larger the retention factor, the larger the improvement

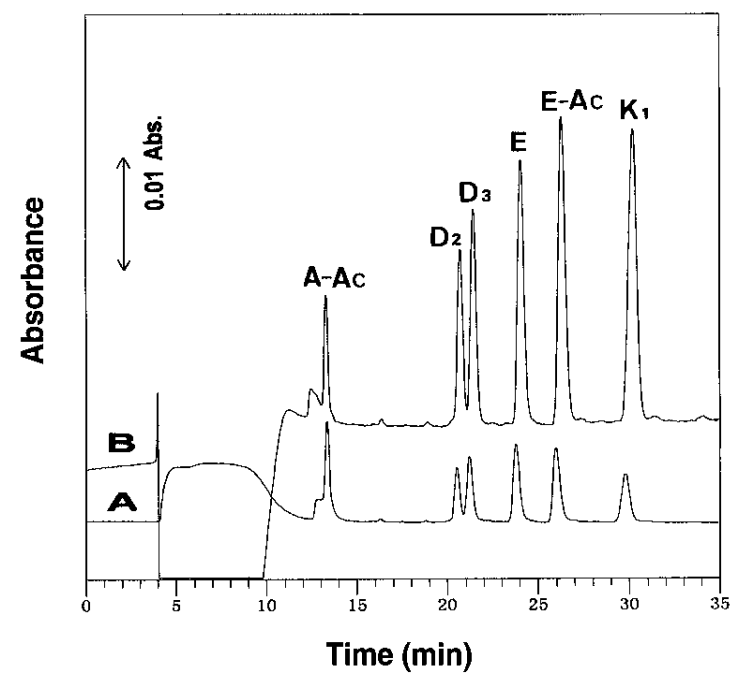

Figure 3. Post-column (A) and on-column UV absorption detection (B) of fat-soluble vitamins. Column, Develosil ODS-UG-5 $150 \times 0.3 \mathrm{~mm}$ i.d.; mobile phase, methanol-acetonitrile (40:60); flow-rate, $4.2 \mu \mathrm{L} / \mathrm{min}$; wavelength of UV detection, $280 \mathrm{~nm}$; flow cells, empty cell (A) or packed cell (B); sample, $0.44 \mu \mathrm{g} / \mathrm{mL}$ of vitamin A-Ac, $0.28 \mu \mathrm{g} / \mathrm{mL}$ of vitamin D2, 0.26 $\mu \mathrm{g} / \mathrm{mL}$ of vitamin D3, $2.5 \mu \mathrm{g} / \mathrm{mL}$ of vitamin $\mathrm{E}, 2.6 \mu \mathrm{g} / \mathrm{mL}$ of vitamin E-Ac and $1.2 \mu \mathrm{g} / \mathrm{mL}$ of vitamin $\mathrm{K} 1$ dissolved in acetonitrile-water (70:30); injection volume, $15 \mu \mathrm{L}$. 
of the detection limits. Under the conditions in figure 3 the peak height ratios of the on-column detection to post-column detection were 4.1 for vitamin E-Ac and 6.2 for vitamin $\mathrm{K} 1$. In addition, it should be noted that the resolution is not deteriorated by the on-column detection.

\section{Conclusions}

The use of a packed flow cell provided a signal enhancement in UV absorption detection similar to fluorimetric detection. On-column UV absorption detection with a packed flow cell improved the detection limits of fat-solu- ble vitamins eluted late, which was due to the focusing effect of the stationary phase in microcolumn LC.

\section{References}

1. Yang, F. J. J. High Resolut. Chromatogr. Chromatogr. Commun. 1980, 3, 589.

2. Yang, F. J. J. High Resolut. Chromatogr. Chromatogr. Commun. 1980, 4, 83.

3. Guthrie, E. J.; Jorgenson, J. W. Anal. Chem. 1984, 56, 483.

4. Takeuchi, T.; Yeung, E. S. J. Chromatogr. 1987, 389, 3.

5. Takeuchi, T.; Ishii, D. J. Chromatogr. 1988, 435, 319.

6. Takeuchi, T.; Ishii, D. Chromatographia 1988, 25, 697.

7. Takeuchi, T.; Miwa, T. Anal. Chim. Acta 1995, 311, 231.

8. Takeuchi, T.; Asano, T.; Ishii, D. J. Chromatogr. 1989, 471, 297. 